\title{
Influence of governance regime on controller roles - supervisory board members' perspectives on business unit controller roles and role conflict
}

\author{
Bert Steens, Anouk de Bont and Frans Roozen
}

\begin{abstract}
Purpose - The plethora of changes in the corporate governance landscape over the past two decades has the potential to tighten governance regimes and influence the preference of supervisory board members vis-à-vis the involved decision-making role of business unit (BU) controllers and their independent fiduciary role. Stricter financial reporting and compliance requirements may lead organizations to prioritize the latter role. However, recent studies support the need to balance these roles, inducing the potential for role conflict. The purpose of this study is to shed light on the influence of a tight and loose governance regime on this balance as preferred by supervisory board members.

Design/methodology/approach - This study uses a unique data set from an experiment among 73 supervisory board members. The authors take their perspective because compliance with governance codes and corporate policies are relevant topics for their function.

Findings - The authors find evidence for the preference of supervisory board members for "all-round" $\mathrm{BU}$ controllers who, irrespective of the governance regime, demonstrate substantial levels of fiduciary and decision-making qualities and deal with the resulting role conflict.

Originality/value - The outcomes of the experiment among supervisory board members provide evidence for their preferences concerning the balance of the two primary controller roles and for the potential of role conflict. The authors have not found studies that provide such empirical evidence.

Keywords Experiment, Controller independence, Controller involvement, Controller role conflict, Governance regime, Supervisory board members

Paper type Research paper

\section{Introduction}

In his pioneering research, Sathe $(1982,1983)$ [1] substantiates the relevance and the merits of independence and involvement as the two major responsibilities of controllers. The involved controller is actively involved in business decision-making, recommends courses of action and challenges the plans and actions of executives using prospective information. The independent controller is responsible for the accuracy and reliability of financial reporting and internal control activities, and has to be objective and independent in dealing with management (Sathe, 1983, p. 36). The value of each of these roles is also supported in more recent literature (Indjejikian and Matějka, 2009; Friedman, 2012, 2014; Merchant and Van der Stede, 2017). However, Sathe's initial research and more recent studies (Maas and Matějka, 2009; Indjejikian and Matějka, 2009; Van der Stede and Malone, 2010) point out that the two roles could be conflicting: involvement could lead controllers to defend managers' stakes and jeopardize independence, and vice versa.
\end{abstract}

Bert Steens, Anouk de Bont and Frans Roozen are all based at the School of Business and Economics, Vrije Universiteit Amsterdam, Amsterdam, The Netherlands.

Received 8 October 2019 Revised 31 January 2020 5 May 2020

Accepted 11 June 2020

(C) Bert Steens, Anouk de Bont and Frans Roozen. Published by Emerald Publishing Limited. This article is published under the Creative Commons Attribution (CC BY 4.0) license. Anyone may reproduce, distribute, translate and create derivative works of this article (for both commercial and noncommercial purposes), subject to full attribution to the original publication and authors. The full terms of this license may be seen at http://creativecommons.org/licences/by/4.0/ legalcode

The authors thanks Henri Dekker, Tom Groot, Luc Quadackers, Frank Verbeeten and ARCA seminar participants at Vrije Universiteit Amsterdam for their helpful comments and contributions. 
The relevance of these roles and their balance is emphasized when they are affected by regulatory corporate governance frameworks (enacted corporate governance codes, such as the Sarbanes Oxley Act of 2002 [SOX]) and corporate internal control policies that together define a company's governance regime. A tight governance regime defined by a rule-based corporate governance act that enforces strict control procedures, such as SOX, could affect the activities of controllers (De Loo et al., 2011) and could result in a different preferred balance than a loose governance regime. The latter is based on a principle-based code that sets standards for the intended outcome and leaves room for less strict controls, such as the Dutch Corporate Governance Code (DGC) (Wieland, 2005). Indjejikian and Matějka (2009, p. 1087) find survey evidence for the assertion that "SOX has made firms much more concerned about the integrity of their financial reports" and, as a consequence, firms motivate their chief financial officers (CFOs) "to focus more on their fiduciary responsibilities."

Via an experimental survey, our study aims to shed light on the influence of the governance regime on the balance of the two main roles of a controller as preferred by supervisory board members. We investigate, in particular, the impact of a tight and loose governance regime on a business unit (BU) controller's degree of independence and involvement and on the potential of role conflict in the view of supervisory board members [2]. We take their perspective because compliance with the relevant governance codes and corporate policies and the effectiveness of controllers performing their fiduciary and decision-making roles are relevant topics for supervisory board members [3]. We define supervisory board members as the non-executive and independent members of a one-tier board of directors, and the members of the supervisory board in a two-tier board structure. The generally accepted function of a supervisory board member is to challenge and support the development of strategy, evaluate the performance of management, safeguard the accuracy of financial information and the robustness and defensibility of financial controls and risk management systems and remunerate, appoint and replace senior management [4]. An organization's governance regime comprises both externally enforced corporate governance regulations and self-imposed internal controls, following Merchant and Van der Stede (2017, p. 573) who assert that "Corporate governance systems and management control systems (MCSs) are inextricably linked." A tight governance regime, as defined by a rule-based governance orientation, has a "comply-or-die" mechanism in place, and has strict internal control practices and formal procedures to comply with the imposed corporate governance rules and regulations. A loose governance regime, on the other hand, is determined by a principle-based governance orientation and uses a "comply-orexplain" mechanism. This regime leaves room for loosely structured and informal control activities that permit and even encourage autonomy, entrepreneurship and innovation (Merchant and Van der Stede, 2017, p. 230).

We respond to the call for further research in this area voiced by Byrne (2009, p. 378). In discussing the outcomes of his study on the antecedents, characteristics and consequences associated with the roles of management accountants (MAs) [5]. Byrne argues that there is a need for more research into the consequences of SOX (i.e. a determinant of a rule-based and tight governance regime) on the roles of MAs.

Using a unique data set from an experiment among 73 supervisory board members, our study contributes to the existing literature as it provides empirical findings regarding the preferences of supervisory board members for the involvement and independence of $\mathrm{BU}$ controllers as a consequence of the tightness of the governance regime, and the potential for role conflict. We have not found studies that provide such empirical evidence.

\section{Development of hypotheses}

\section{1 Controller's roles}

The traditional role of controllers (as defined in 1963 by the Financial Executives' Institute) [6] has often been characterized as that of bookkeeper, scorekeeper, corporate policeman, 
financial historian and, less elegantly, bean counter (Colton, 2001; Merchant and Van der Stede, 2017; Russel et al., 1999). The main responsibility connected with this role lays with the accuracy and reliability of financial reporting about past events to management. The traditional role has primarily been connected with providing assurance and credibility to the organization's basic financial processes and accounting systems that record and process financial transactions and generate standard reports on the financial performance in accordance with the relevant accounting and performance measurement standards (Sathe, 1982; Windeck et al., 2015; Merchant and Van der Stede, 2017). This fueled the perception of the controller as the financial conscience of the organization (De Loo et al., 2006). The traditional role placed a strong emphasis on the controller's independence because it would reduce the controller's temptation to manipulate financial statements and reports in favor of the managers accountable for the financial results. Merchant and Van der Stede (2017, p. 631) assert that:

[...] as chief accountants for their entities, controllers must stay appropriately independent of their entity managers. They have a fiduciary responsibility to ensure that the information reported from their entity, particularly that of financial nature, is accurate and the internal control systems are adequate. They have a management oversight responsibility to inform others inside and outside the organization [.. . ] if individuals in their entity are violating laws or ethical norms.

At the time, the contributions of Sathe (1982) and Hahn (1982) were relevant in the light of the lively debate on the merits of extending a controller's traditional, merely accountingrelated activities to management support activities. In the 1990s, the scope of the controller's activities appeared to have broadened to helping managers make good business decisions (Merchant and Van der Stede, 2017, pp. 629-631), increasing the managerial involvement of controllers. As Colton (2001, p. 1) states: "The controller is welcomed into the halls of management as a business partner, sought after for business acumen and the strategic perspectives." Weber (2011, p. 25 and 42) describes the development of controllership as a "progression to a higher level of additional responsibilities and functions." Friedman $(2012,2014)$ uses the term "strategic partner" to mark the distinct collaborative decision-making relationships of finance within the executive management team. Chang et al. (2014, p. 4) assert that:

[...] in addition to measuring and providing decision-support data for current operations, finance organizations are being called upon to take a greater direct role in the development and implementation of enterprise strategy.

Increasing the involvement of controllers in management by supplementing the traditional independent financial reporting role with a decision support role has been documented elaborately (Hahn, 1982; Sathe, 1982; Burns et al., 1996; Granlund and Lukka, 1998; Burns and Scapens, 2000; Colton, 2001; IFAC [International Federation of Accountants], 2002; Joseph, 2006; Howell, 2006; Roozen and Steens, 2006; Scapens, 2006; Järvenpää, 2007; Van der Stede and Malone, 2010; Graham et al., 2012; Friedman, 2012, 2014; Chang et al., 2014; Windeck et al., 2015; Merchant and Van der Stede, 2017).

The independent role and the involved role of the controller are also understood in terms of the controller's dual reporting lines. Consistent with the models of Hahn (1982, pp. 21-50), Anthony and Govindarajan (2007, pp. 111-112) and Merchant and Van der Stede (2017, pp. 629-633), BU controllers have divided loyalties, owing some allegiance to the corporate controller and some to the BU management. The controller can have a hierarchical (primary) or functional (secondary) reporting line to the $\mathrm{BU}$ management and the corporate controller/CFO. Arguably, the controller's accountability to the corporate controller emphasizes the controller's independence from BU management, whereas his or her accountability to the $\mathrm{BU}$ management emphasizes the controller's involvement (Merchant and Van der Stede, 2017, p. 633). 
Combining (involved) management support activities with the traditional (independent) role has certain pros and cons. Some argue that emphasizing one role at the expense of the other would make the controller's overall contribution less effective. They prefer "all-round" controllers who balance independence and involvement (De Loo et al., 2011; Van der Stede and Malone, 2010). De Loo et al. (2011, p. 303) warn for overly focusing on the involved business partner role and argue that although the environment of organizations is changing, an exclusively business-oriented MA will not be called for in the future, and that scorekeeping and other internally oriented activities will remain to form a major part of the daily work of MAs. The importance of this broader role is also supported by a survey study by Van der Stede and Malone (2010) as they warn for not extending the traditional (independent) scorekeeper role with the (involved) business partner role. They find that:

[...] keeping the numbers in order no longer spans the entire extent of an accountant's reach. Those who continue to embrace old skills exclusively will likely be left behind. Those who embrace their expanding roles and responsibilities with competence and integrity will be in demand. But as they become even more closely connected with the business, they must also ensure to not become subservient to it (Van der Stede and Malone, 2010, p. 11).

Others state that combining the two roles could lead to role conflict. An emphasis on independence may make the controller less privy to sensitive management information and deliberations during the decision-making process, limiting the scope of the controller to after-the-fact or reactive control. By playing a fully independent role toward head office, the controller runs the risk of being sidelined from relevant business information, which lies at the heart of the decision-making process (Lambert and Sponem, 2005). In contrast, a controller who is actively involved in management decision-making is fully informed and can perform anticipatory control to head off potential problems (Sathe, 1982). This is consistent with the findings of Byrne and Pierce (2007, p. 492) that "challenge the argument that [management] accountants require complete independence for effective management control" and their conclusion that "findings show the combined control and partnership role as most common" and that role conflict is "a necessary phenomenon." Similarly, Graham et al. (2012, p. 84) conclude that the enlarged role of controllers "[h]as increased their overall workload and brought about frustration." So, while recent studies confirm the relevance of the two roles, they also recognize the potential for conflict (Byrne, 2009; Byrne and Pierce, 2007; Maas and Matějka, 2009; Van der Stede and Malone, 2010; Graham et al., 2012; Merchant and Van der Stede, 2017).

Consistent with these findings, Chang et al. (2014, p. 30) find that the importance placed on financial roles increases the effectiveness of the finance function. They concur that this effect could justify the coexistence of theoretically conflicting roles but conclude that:

[...] although these conflicts may exist, our evidence suggests that the majority of firms in our sample have been able to manage them and, in some cases, to generate positive spillover effects from the various roles.

Several studies point at measures that help realize conditions for effectively balancing potentially conflicting roles (Indjejikian and Matějka, 2009; Maas and Matějka, 2009; Sathe, 1982).

Overall, this suggests that finding the right balance between independence and involvement assumes awareness of the fact that both roles are necessary but could be conflicting.

\subsection{Influence of corporate governance on governance regime}

In the past decades, the attention paid to corporate governance has increased enormously (Aguilera and Cuervo-Cazurra, 2009; Horngren et al., 2015, pp. 38-39; Merchant and Van der Stede, 2017, pp. 573-574). This is driven by the high-profile collapses of a number of 
large US and European firms. In response, countries have introduced regulatory and legislative initiatives focused on the roles and responsibilities of management and boards of directors with respect to financial reporting and internal control systems (Merchant and Van der Stede, 2017, pp. 574-575). Most corporate governance codes contain recommendations about governance practices related to the structure and responsibilities of the board of directors, timely and quality information to the board, balanced and understandable financial reporting and maintaining a sound system of internal controls (O'Shea, 2005, cited in Aguilera and Cuervo-Cazurra, 2009, p. 377). According to Busco et al. (2007), this focus on the trustworthiness and reliability of financial reports and the requirements of internal controls have directly influenced the finance function. Furthermore, Roozen and Steens (2006) argue that corporate governance requirements can influence organizations' governance regimes by placing higher demands on internal governance and controls resulting in higher levels of bureaucratization, more formal and legalistic approaches to business and accounting practices and legal codification. Similarly, Byrne (2009) reports that SOX appeared to have strengthened the control environment, and Merchant and Van der Stede (2017, p. 130) assert that:

[...] as a consequence of the required compliance with Section 404 of the [Sarbanes-Oxley] Act, many public companies in het United States have both improved the documentation of their internal controls and tightened them up.

Consequently, governance regimes may tighten, leaving less room for loosely structured practices and informal coordination and control of activities.

Corporate governance orientations vary widely across countries (Aguilera and CuervoCazurra, 2009, p. 383; Merchant and Van der Stede, 2017, pp. 573-575). Generally, there are two major corporate governance orientations that distinguish the strictly regulated rulebased governance mechanisms from the relatively loose, principle-based governance mechanisms. [7] A particular governance regime can therefore be described in terms of its relative tightness or looseness (Merchant, 1985, pp. 57-67). The tightness (and therefore also the looseness) of a governance regime is a function of whether the corporate governance orientation is rule-based or principle-based and of the amount of control and certainty the organization's internal controls can provide (Merchant, 1985). A rule-based governance orientation will stimulate tight control policies owing to its strict rules and regulation, while a principle-based governance regime allows loose control policies.

\subsection{Influence of governance regime on controller roles}

The growing emphasis on compliance and transparency in corporate governance has placed increased pressure on organizations' control functions (Feeney and Pierce, 2007, p. 21). Strict compliance to legislation and guidelines may account for a return to the reliability of information as their main focus (Roozen and Steens, 2006). The renewed emphasis on reliable and honest financial data is expected to make the controller's independence more important. This is consistent with the finding of Indjejikian and Matějka (2009, p. 1087) that public companies focus more on their fiduciary responsibilities related to the integrity of their financial reports' in response to the post-SOX increase in the cost of misreporting. Moreover, Byrne (2009) reports that MAs indicated that an increasingly dominant regulatory environment challenges fulfilling the business partner role. In highly regulated environments (e.g. SOX), controllers have to deal with an additional regulatory burden that increases their workload, potentially resulting in less time for business partnering (Byrne, 2009).

This suggests that, ceteris paribus, a tight governance regime leads to prioritizing the independent role of the controller, while a loose governance regime will leave more room for the involved role, which then - according to Colton (2001) and Chang et al. (2014) - will be gladly accepted. But literature also supports the relevance of fulfilling both roles and the expectation that the pressure to prioritize one of the two roles will be countered by the need 
to balance independence and involvement (De Loo et al., 2011; Van der Stede and Malone, 2010). The potential consequence of role conflict will be dealt with (Chang et al., 2014; Indjejikian and Matějka, 2009; Maas and Matějka, 2009).

The influence of the governance regime on the roles of the $\mathrm{BU}$ controller inducing role conflict can be viewed as an agency problem with one agent (BU controller) and two principals (the BU controller's functional superior and hierarchical superior). Following the general principal-agent constructs set out by Jensen and Meckling (1976, pp. 308-310), Eisenhardt (1989, pp. 57-64) and Wieland (2005, pp. 79-81) and the specific properties of the setting with two principals (Brent, 1999; Larsén, 2007; Gailmard, 2009), the BU controller (agent) is assigned by the controller's superiors (principals) to fulfill the two main roles of the controller in the principals' interests. One principal is the BU manager and the other is the CFO (possibly through the corporate controller). The principals' interests consist of optimizing their welfare and minimizing the agency costs. Their welfare depends on two factors: the degree of meeting the requirements of the governance regime (fiduciary factor) and the quality of the business decisions made by BU management (decision-making factor). Agency costs consist of the cost of monitoring the controller's actions (using the controller's two reporting lines), the bonding expenditures by the controller (e.g. extra effort required to serve both principals and handling role conflict) and deviations of the controller's actions from those that optimize the principals' welfare (moral hazard or conflict of interest). Not optimizing the welfare of one or each principal and occurring agency costs can be the consequence of principals attributing different weights to the factors that determine their welfare, and therefore to the two reporting lines and roles of the controller. Unbalanced roles are expected to be avoided, following De Loo et al. (2011) and Van der Stede and Malone (2010). In this agency model setting, this means that the pressure to prioritize one of the two roles as a result of one of the two elements in the welfare function of one of the principals is expected to be countered by the influence of the other element and different weights in the other principal's welfare function, and additional bonding and monitoring efforts. If, for instance, a tight governance regime leads the CFO to give more weight to the fiduciary factor than to the decision-making factor of the welfare function, the CFO will demand from the controller to allocate more time to the independent role. This is expected to be countered by the BU manager acting on the decision-making factor in his or her welfare function. In addition, the monitoring efforts by both principals and extra efforts by the agent to satisfy both principals contribute to balancing the two roles. This requires that the two principals have to agree on the controller's objectives, the way the corresponding impact on their joint and individual welfare is dealt with and the agency costs. Principals limit the agency costs by including incentives (remunerations and appraisals) in the contract and monitoring the agent's actions.

\subsection{Hypotheses}

Literature provides support for the expectation that the pressure to prioritize the $\mathrm{BU}$ controller's independent (involved) role at the expense of the other role as a result of a tight (loose) governance regime, will be countered by the need to balance the two roles (De Loo et al., 2011; Van der Stede and Malone, 2010). Maintaining the balance of the two roles in case of a governance regime that emphasizes one of the roles has the potential consequence of role conflict which will be managed (Chang et al., 2014; Indjejikian and Matějka, 2009; Maas and Matějka, 2009). Effectively handling role conflict resulting from leveling one role (e.g. the involved role) with the increased emphasis on the other (e.g. when independence is stressed as a result of a tight regime) allows firms to maintain the advantageous balance between controller independence and involvement, regardless of the influence of the governance regime they are exposed to. We expect that supervisory board members recognize the importance of both roles and their balance, because they are responsible for overseeing the compliance with rules and regulations and the quality of 
business decision-making, which are both vital for the sustainability of the company. In addition, we expect that supervisory board members require management to establish the conditions for a balanced fulfillment of both roles (e.g. by setting targets for the controller that are agreed upon by all superiors). We formulate our first hypothesis accordingly.

H1. Both the preferred degree of $\mathrm{BU}$ controller independence and the preferred degree of $\mathrm{BU}$ controller involvement are equally substantial under a tight and a loose governance regime.

Following Maas and Matějka (2009), who found that "the emphasis on the functional responsibility of $\mathrm{BU}$ controllers is positively associated with role conflict and role ambiguity," we hypothesize that a tighter governance regime leads supervisory board members to recognize the importance of the independent role while supporting the balance with the involved role, and - as a consequence - that they assume controller role conflict.

H2. The independent $\mathrm{BU}$ controller role and the involved $\mathrm{BU}$ controller role are perceived to be potentially conflicting roles.

\section{Data}

\subsection{Research method}

For testing $\mathrm{H} 1$ and $\mathrm{H} 2$, we use data obtained from a cross-sectional randomized two groups post-test only experiment (Albers and Kratochwill, 2010, pp. 126-127) executed for the Dutch association for supervisory board members [Nederlands KennisCentrum voor Commissarissen (NKCC)] between mid-2009 and early 2012. The target group consisted of 526 supervisory board members who were members of the NKCC at the time.

The manipulation (independent variable), the governance regime tightness, was implemented by using two versions of a case that describes the setting of an organization, its governance regime and its finance function. The two versions of the case only differ for the governance regime tightness. We expect the supervisory board members to develop an unbiased preference for the BU controller's role based on the (tight or loose) setting of the case, as it is their role to act in the interest of the enterprise and recognize that both roles serve the realization of the firm's goals. By means of randomization, half of the sample received a case with the tight governance regime (G1), and the other half received a case with the loose regime (G2). Randomization gave each participant an equal probability of being selected for a particular case, thereby controlling for the effects of individual differences in background and experience.

The key strength of experimental research is that it allows strong causal inferences to be made, also in case of lacking sufficient archival data or when the conditions under study do not presently exist (Trotman et al., 2011, p. 280; Ham et al., 2017, p. 1103). Therefore, experiments are noted as important for judgment and decision-making (JDM) research (Trotman et al., 2011, pp. 279-280). A major benefit of experiments is that the researcher creates the experimental setting to examine the effect of the independent variable(s) of interest (the manipulation) on the dependent variable(s) in the relevant setting, while at the same time controlling for other factors that potentially affect the dependent and independent variables and their relationships (Trotman et al., 2011, p. 280). Because of the specific JDM setting in our study, archival data are not available or would require highly disputable proxies, whereas an experiment allows us to focus on the specific impact of the governance regime (independent manipulation variable) on the level of independence and involvement of the BU controller as preferred by supervisory board members (dependent variables) while controlling for influences of the attributes of the participating supervisory board members.

A common limitation of experimental research is that it could fail to capture potential influences that exist in real-world situations, narrowing the generalizability of the results 
(Ge et al., 2011, p. 1145). In response to this limitation, we use a unique sample of experienced supervisory board members and case descriptions featuring the attributes of the variables under study in accordance with literature.

\subsection{Sample}

We obtained the data by purposive sampling (Kerlinger, 1986). Out of 526 supervisory board members, 73 (13.9\%) responded. Table 1 below summarizes descriptive information concerning the number of respondents. The different sizes of the subsamples per case are a consequence of the randomization.

\subsection{Case descriptions}

The case concerns a listed company that is exposed to an enacted governance regime and that faces disappointing financial results and requires the contributions of the independent and involved controller roles. We incorporated the key concepts from literature into the case description. One company description detailed a tight governance regime, while the other detailed a loose regime. The company exposed to the tight regime is listed on the New York Stock Exchange. It has to deal with SOX and, consequently, operates with a rules-based approach. To emphasize the tightness of the governance regime, the description includes pivotal principles of SOX [e.g. the sign-off on the effectiveness of internal control systems as required by Section 404, referring to Merchant and Van der Stede (2017), and the application of the "comply-or-die" mechanism, referring to Calder (2008)] and tight control practices [the way it specifies and communicates desired results and action, measures results and imposes behavioral constraints, referring to Merchant and Van der Stede (2017)]. The company in the loose case is listed in Amsterdam (AEX) and deals with the principle-based DGC. The description comprises main principles of the DGC [e.g. the comply-or-explain mechanism and the self-responsibility of the company, referring to Cromme (2005)] and loose control practices. The loose governance regime permits autonomy, and has room for entrepreneurship, innovation, as well as loosely structured and informal coordination and control activities.

To bring into play the two controller roles, the case description features a chief executive officer who organizes a board meeting for discussing two items: the preliminary financial results prepared by the $\mathrm{BU}$ controller and how to deal with the disappointing results of the $\mathrm{BU}$. The first item reflects the traditional independent role of the BU controller, emphasizing the responsibility for the accuracy and reliability of the (after-the-fact) financial reporting of the BU. The second item reflects the role of the BU controller as an involved business partner, emphasizing the anticipatory role.

\subsection{Questionnaire}

After reading the case description, the questionnaire informs participants about the concepts "independence" and "involvement." Participants were asked to provide two separate scores on a five-point Likert scale for the levels of controller independence and controller involvement preferred by them for the case organization. Next, respondents were

Table 1 Number of respondents of the experiment and the division between tight and loose case

No. of respondents 
asked to indicate how the $\mathrm{BU}$ controller should operate in relation to the $\mathrm{BU}$ management on the continuum from totally involved to totally independent using a five-point Likert scale, in accordance with Van der Stede and Malone (2010). This question was included to allow for expressing a different or similar priority level. As the two roles are also understood in terms of their hierarchical reporting lines (solid lines in Figure 1) and functional reporting lines (dotted lines in Figure 1), the questionnaire asks to check the preferred reporting model out of the options outlined in Figure 1. In addition, we included control questions to check whether the respondent noticed the organization's governance regime.

General questions were included to gather data for our control variables (age, gender, years of work experience, number of listed companies worked for, occurrence of compliance and internal control problems within these listed companies, experience with governance codes and knowledge of governance codes).

Table 2 summarizes the variables that correspond with the questions in the questionnaire and presents the descriptive information for each of the variables (variable names are in italics).

\section{Data analysis and results}

\subsection{Manipulation check}

We performed a manipulation check by conducting a one-sided two-sample $t$-test on the two groups of observations of the variable Tightness defined by the grouping variable Regime, after accepting the normal distribution for two groups of observations of Tightness. Tightness expresses the perceived tightness of the governance regime. Regime is the binary variable for the governance regime represented by the case description (0: tight case; 1: loose case). To rule out failure of the treatment, we require that the scores of the respondents who received the tight case are higher than those of the respondents who got the loose case. We also conducted a similar test on the obtained scores for Freedom (perceived degree of entrepreneurial autonomy of the management of the case organization). Consistent with Cromme (2005), it is expected that the perceived entrepreneurial autonomy for the tight case does not exceed the perceived entrepreneurial autonomy for the loose case. Furthermore, the correlation and the association between the variables Regime and Perceived governance code (expressing the external governance regime as perceived by the respondents; 0: SOX; and 1: DGC) are used to verify whether the respondents have correctly recognized the governance regime. A significant positive correlation and a significant association between these variables support correct recognition.

The descriptive information of Table 2 is divided between supervisory board members who received the tight case $($ Regime $=0)$ and those who received the loose case $($ Regime $=1$ ).

\section{Figure 1 Reporting lines of a BU controller}

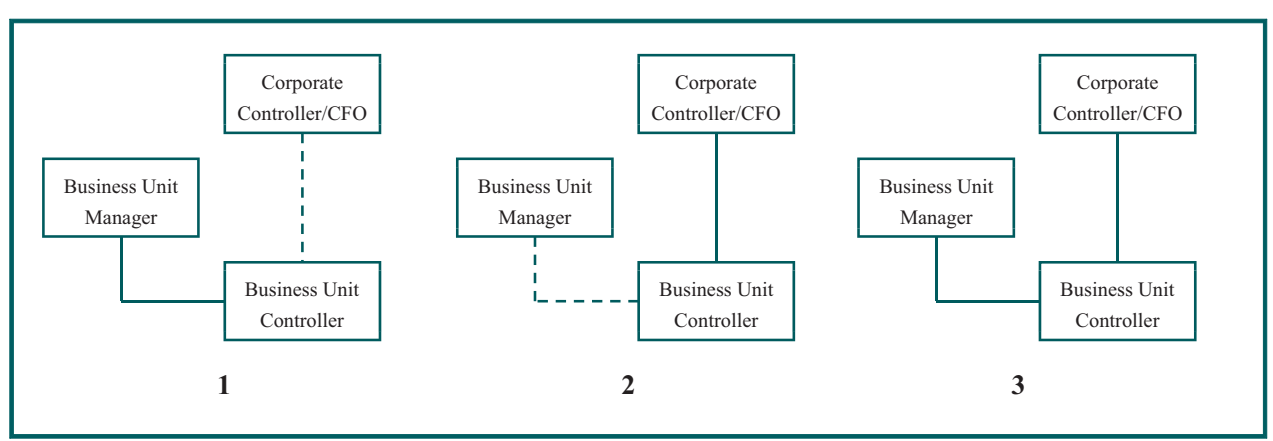

\begin{tabular}{l|l|l} 
VOL. 20 NO. 62020 & CORPORATE GOVERNANCE & PAGE 1037
\end{tabular} 


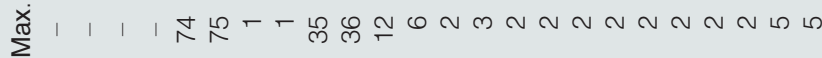

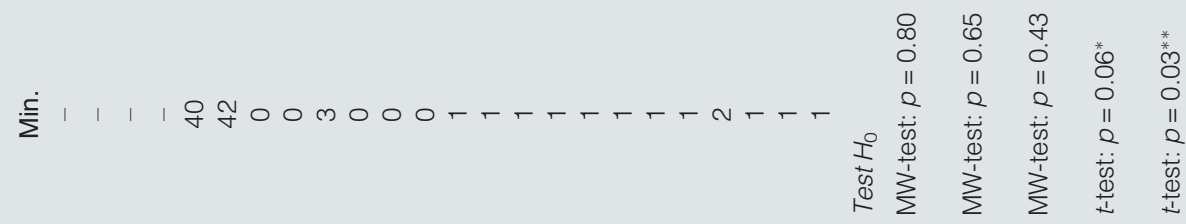

$\cos$

mi

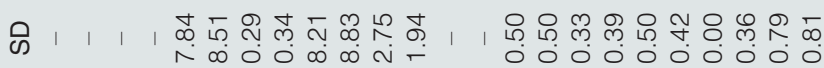

II

\& \&

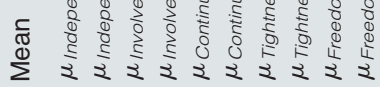

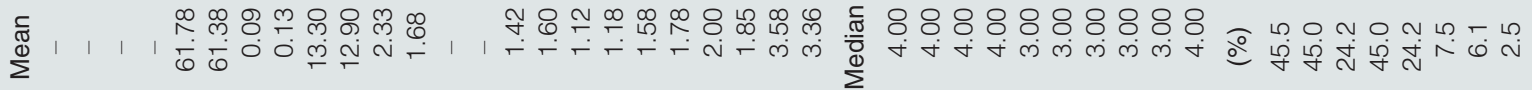

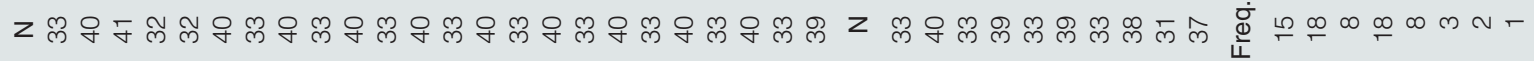

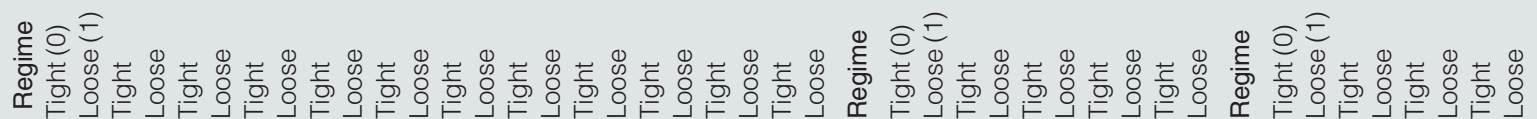

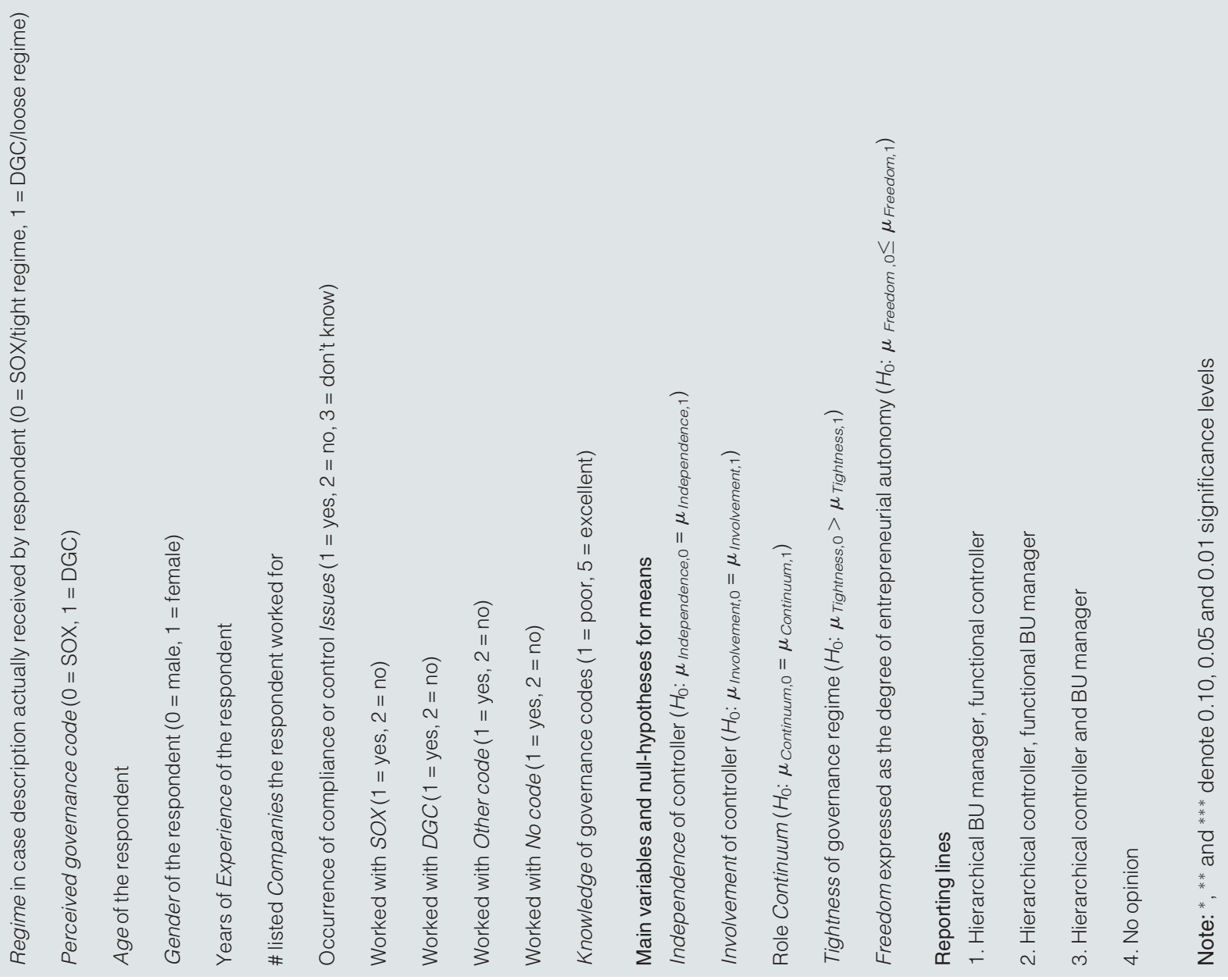


The differences between the means of Tightness for the two groups of responses are as required. The one-sided two-samples $t$-test for testing the null-hypothesis $\mu_{\text {Tightness }, 0}>$ $\mu_{\text {Tightness, } 1}$ produced a $p$-value of $0.06^{*}$ [the adjusted $\chi^{2}(2)$ value and related $p$-value resulting from the skewness/kurtosis-test for normality are 2.41 and 0.30 for the tight case and 0.71 and 0.70 for the loose case causing no concerns relating to the normality assumption; and equal variances were not rejected by Bartlett's and Levene's tests]. This outcome confirms the effectiveness of the manipulation accepting a type I error of 0.06 as the corresponding power-to-alpha likelihood ratio exceeds 8 (32) when $p(H O=$ true $) \leq 0.47$ (0.18). [8] The outcome of the same procedure for testing $\mu_{\text {Freedom, } 0} \leq \mu_{\text {Freedom }, 1}$ is confirmative as the $p$-value equals $0.03^{* *}$ [the adjusted $\chi^{2}(2)$ value and related $p$-value resulting from the skewness/kurtosis-test for normality are 1.01 and 0.60 for the tight case and 2.33 and 0.31 for the loose case, causing no concerns with regard to the normality assumption and equal variances were not rejected; and the power-to-alpha likelihood ratio exceeds 8 (32) when $p(H O=$ true $) \leq 0.75(0.43)]$.

Table 3 shows Pearson's pairwise correlations. The significant correlation between Regime and Perceived governance code confirms that the respondents have correctly interpreted the external governance regime. This finding also results from applying Pearson's chi square association test for these two variables $\left[\chi^{2}(1)=6.711 ; p=0.01^{* * *}\right]$. As expected, the correlation between Tightness and Regime is negative, and the correlation between Freedom and Regime is positive and significant. The correlation between Freedom and Perceived governance code is positive (as expected) but insignificant. The correlation between Freedom and Tightness is significantly negative which is as expected too.

The recognition of the governance regimes is also supported by the reporting line preferences (Figure 1). Based on Table 2, most respondents given the tight case (45.5\%) prefer model 1 in Figure 1 while models 1 and 2 were equally preferred by the respondents given the loose case (both $45.0 \%$ ). Of the total sample, $45.2 \%$ prefer model 1 and $34.6 \%$ prefer model 2. The strongly negative correlation between Involvement and Reporting line (Table 3) means that a higher (lower) preferred degree of involvement corresponds with a hierarchical (functional) reporting line to the BU manager (corporate controller). [9] The correlation between Independence and Reporting line is only weak.

As expected, Table 3 shows a negative relationship between Independence and Involvement and a strongly positive (negative) correlation between Independence (Involvement) and Continuum. Neither Independence nor Involvement nor Continuum correlate with the governance regime, although the governance regimes were recognized.

\subsection{Testing the influence of governance regime on controller role preference $(\mathrm{H} 1)$}

For testing $\mathrm{H} 1$, we compared the answers of supervisory board members who received the tight case with the responses for the loose case. The two samples for each of the variables (Involvement, Independence and Continuum) consist of unpaired observations, as they represent two groups of respondents who independently gave their opinion based on the description they received, not knowing the other respondents nor the existence of another description. Furthermore, we compared the paired observations for Involvement and Independence for each of the two cases and (one-sidedly) tested whether their means and the mean of Continuum exceed 3. We applied the skewness/kurtosis-test and the Shapiro-Wilk test to check whether the two groups of observations of each of the three variables follow a normal distribution. These tests only rejected the normal distribution of the observed scores for Independence for the loose case, even though some of the groups have values for skewness and kurtosis around their critical values. For that reason, we applied both parametric tests ( $t$-test, ANOVA and ANCOVA) and non-parametric tests (Kruskal-Wallis test and Wilcoxon signed rank test). We checked the required equality of variances by means of Bartlett's test and Levene's test. For the ANCOVA, we controlled for the effects of the control variables serving as covariates (Age, Gender, Experience, 


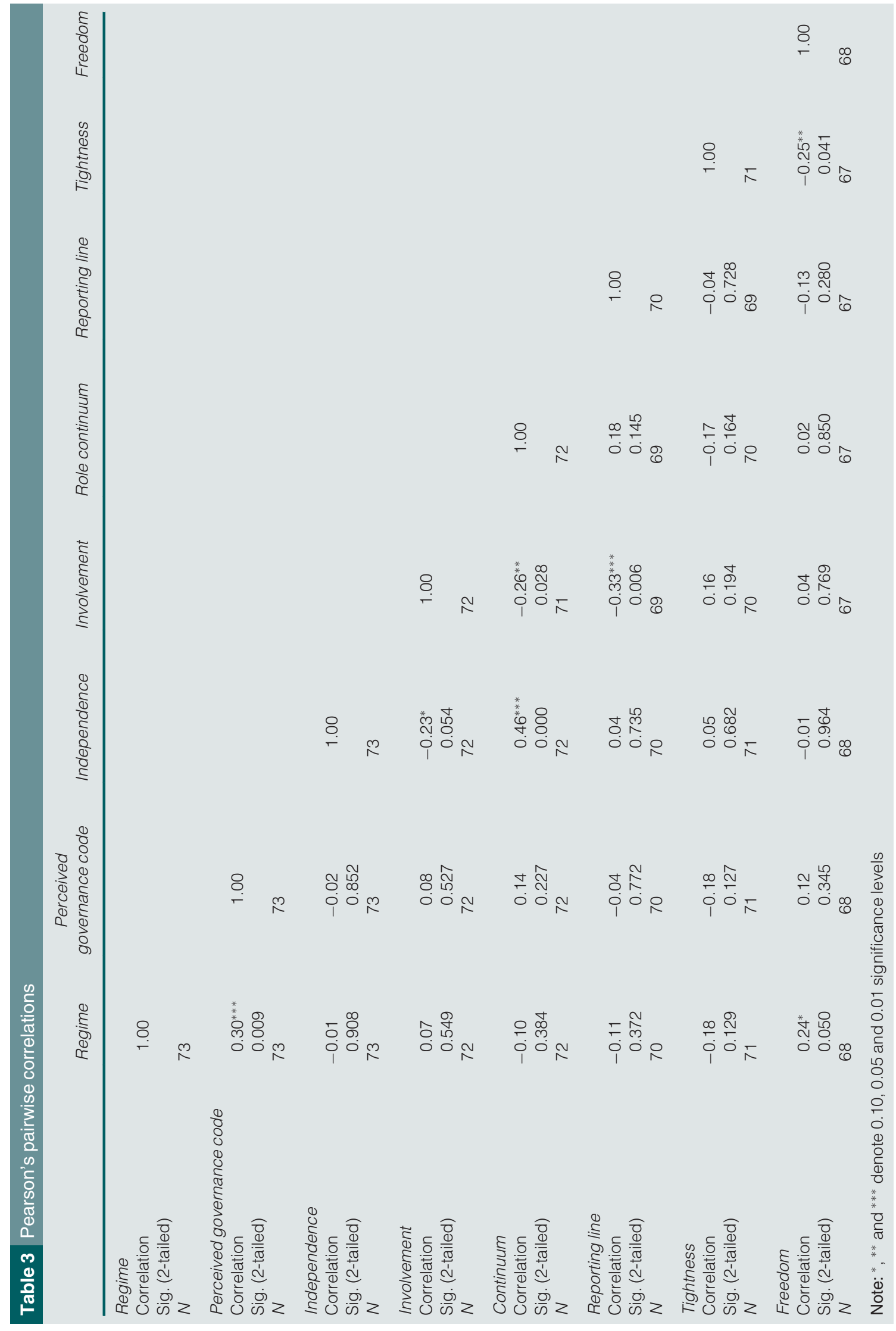


Companies, Issues and Knowledge). We conducted the required robustness tests for confirming equal scores of the covariates across the two groups and equal regression coefficients expressing the relation between a covariate and the dependent variable.

In accordance with $\mathrm{H1}$, the expectation is to obtain test outcomes that fail to reject the nullhypothesis of equal means for the two groups. But, the more similar the observations for the two groups are, the smaller the unknown $p(H 1=$ true $)$ and the larger the sample size need to be for exceeding the threshold for the power-to-alpha likelihood of this test. Therefore, we followed the suggestions of critics of traditional null-hypothesis significance testing (NHST) (Reiser and Faraggi, 1999; Fan, 2001; Cumming and Fidler, 2005; Smith and Morris, 2015) and also analyzed the effect size (using Cohen's $d$, Hedges' $g$ and Glass' delta 1 and delta 2 statistics) and the 95\% confidence intervals and their overlapping proportions. Furthermore, we compared the distributions of the two groups of observations of each of the three variables, applying the chi-squared test. Small effect sizes, largely overlapping 95\% confidence intervals and equal distributions support $H 1$.

Figure 2 presents the results of performing the outlined procedure for testing $\mathrm{H} 1$. The highly significant $p$-values for rejecting $\mu \leq 3$ for each of the two groups of observations for Independence and Involvement (reported in Panel A of Figure 2) support the expected substantial levels of controller independence and involvement. The significant $p$-value for rejecting $\mu \leq 3$ for those observations of Continuum that reflect the tight case $\left(p=0.01^{* * *}\right)$ would point at prioritizing the independent role under a tight governance regime. For the loose case we found a less significant priority for the independent role $\left(p=0.06^{*}\right)$.

The outcomes of the ANOVA, Kruskal-Wallis and ANCOVA tests (reported in panels A and C) indicate that neither the preferred level of independence nor the preferred level of involvement nor the preferred score on the role continuum can be explained by the difference between a tight and a loose governance regime. So, the null-hypothesis of equal means of the two groups of responses cannot be rejected. Also, the $p$-values resulting from the chi-squared test (panel A) do not point to different distributions for the two subgroups and fail to reject the null-hypothesis of equal means.

The statistically insignificant results (that fail to reject the null-hypothesis of equal means) reflect the similar responses for the two cases, which is as predicted. These outcomes are meaningful as the respondents have clearly recognized the governance regime they worked with. Exceeding the threshold for the power-to-alpha likelihood that would statistically support the relevance of retaining the null-hypothesis would require a very small value for the unknown $p(H 1=$ true), which is not witnessed by our group of respondents, and a very large sample size (thousands of respondents), which is not or hardly feasible.

For that reason, we followed the critics of the traditional NHST who advocate adding effect size and confidence level interval comparisons to the analyses. Statistically insignificant results can be practically significant (because of a large effect size), and vice-versa (Fan, 2001). As expected, also the effect size is small (Panel A), meaning that the manipulation hardly affected the preferred levels of independence and involvement. We therefore follow Fan (2001, p. 282) by concluding that the "null-hypothesis is favored both statistically and practically."

A similar conclusion can be drawn from the $p$-values resulting from the paired $t$-test and paired Wilcoxon signed rank test for comparing the means of independence and involvement for the tight case (0.91 and 0.61) and the loose case (0.58 and 0.96) together with the small effect sizes for the tight case (Cohen's $d=0.03$ ) and the loose case (Cohen's $d:-0.14)$. This conclusion contradicts the rejection of $\mu \leq 3$ for each of the two groups of observations of continuum.

Following the approaches suggested by (a/o) Reiser and Faraggi (1999), Cumming and Fidler (2005) and Smith and Morris (2015), we also added a comparative analysis of the 


\section{Figure 2 Results comparisons of means, (co-)variances, distributions, effect size and confidence intervals}

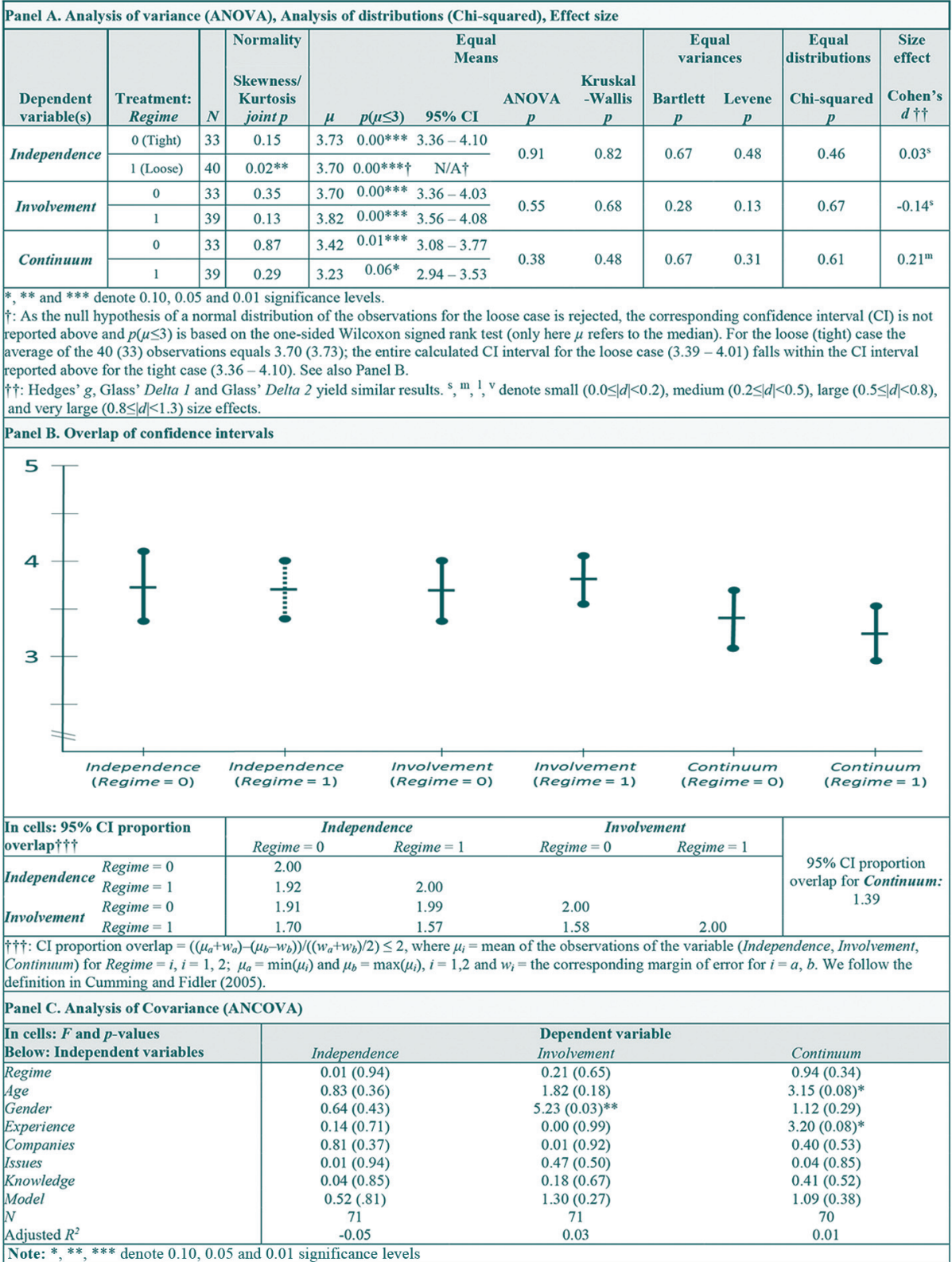

95\% confidence intervals of the relevant outcomes. We found high values for the confidence interval proportion overlap measure (panel B) supporting $H 1$.

Overall, our test results provide support for $\mathrm{H1}$ as they demonstrate a significant manipulation effect and support a preference for substantial levels of involvement and independence, which are similar under a tight and a loose governance regime.

\subsection{Testing the perceived existence of role conflict ( $\mathrm{H} 2)$}

For testing $\mathrm{H} 2$, we developed constructs representing role conflict. For each construct, we measured the actual value per respondent and tested whether the sample mean 
significantly exceeds the average of all values the construct can take (given the options for the response for the underlying variables). For developing the construct, we used composite measures that reflect the two essential dimensions of role conflict. The first dimension is the score spread between the role preferences, measured by the absolute value of the difference between the observed preference scores [equation (1)].

$$
\text { ScoreSpread }=\mid \text { Independence }- \text { Involvement } \mid
$$

The greater the score spread the less equal the weight associated with the two roles and therefore the smaller the tension stemming from balancing the roles. However, the same score spread for higher scores on the two controller roles should express a greater degree of role conflict. For example, a score spread of 1 for the scores 3 and 4 should represent a higher degree of role conflict than the same score spread for scores 2 and 3 . Therefore, the score level expressing the average of the two role preference scores is the second dimension [equation (2)].

$$
\text { ScoreLevel }=(\text { Independence }+ \text { Involvement }) / 2
$$

The value of a construct expressing role conflict should decrease with increasing score spread and should increase with increasing score level (e.g. a relatively low score on ScoreSpread and a high score on ScoreLevel should lead to a high level of role conflict (Figure 3).

We developed six alternative definitions for the construct of role conflict (Conflict $t_{x}$, $x=1, ., 6)$ that meet the required relationship with ScoreSpread and ScoreLevel [equations (3)-(8)].

\section{Figure 3 Role conflict as a function of ScoreSpread and ScoreLevel}

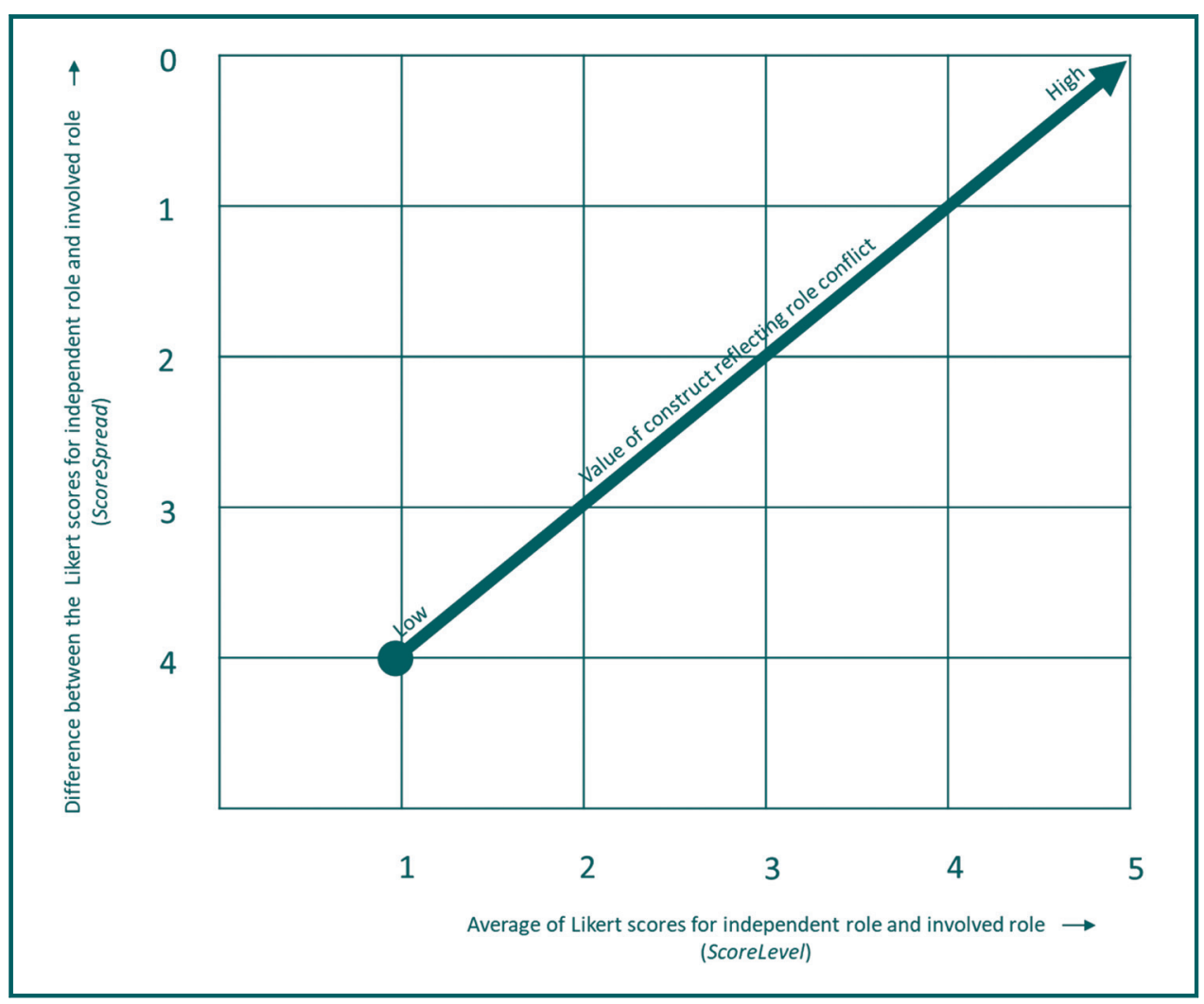

VOL. 20 NO. $62020 \mid$ CORPORATE GOVERNANCE $\mid$ PAGE 1043 


$$
\begin{aligned}
& \text { Conflict }_{1}=\text { ScoreSpread } \cdot \text { ScoreLevel } \\
& \text { Conflict }_{2}=\sqrt{ } \text { Conflict }_{1} \\
& \text { Conflict }_{3}=\operatorname{Ln}\left(\text { Conflict }_{1}\right) \\
& \text { Conflict }_{4}=M+1-\text { AverageRank }\left(\text { Conflict }_{1}\right) \\
& \text { Conflict }_{5}=\text { ScoreSpread }+ \text { ScoreLevel } \\
& \text { Conflict }_{6}=M+1-\text { AverageRank }\left(\text { Conflict }_{5}\right)
\end{aligned}
$$

We verified the validity of each construct by analyzing the relationship between the construct (Conflict ( $_{x}$ and independence and involvement. A greater level of role conflict is expected when roles are more balanced (i.e. have scores closer to each other) and more substantial (i.e. have higher scores). Using the actual scores for independence and involvement received from our respondents, we calculated the corresponding values for the implied level of role conflict, Conflict $x, x=1, ., 6$ in accordance with the definitions represented by equations (3)-(8).

Using these values, we estimated equation (9) using multivariate regression analysis and tested the coefficients $\beta_{1}$ and $\beta_{2}$ (for independence and involvement) for having the same sign and significant and overlapping 95\% confidence intervals taking into account six control variables $\left(C V_{j}, j=1, ., 6\right.$ age, gender, experience, issues, companies and case). [10]

$$
\text { Conflict }_{x}=\beta_{0}+\beta_{1} \cdot \text { Independence }+\beta_{2} \cdot \text { Involvement }+\sum_{j=1}^{6} \beta_{j+2} \cdot C V_{j}+\varepsilon_{\text {Conflict }}
$$

\begin{tabular}{|c|c|c|c|c|c|c|c|c|}
\hline & Predicted & $x=1^{\mathrm{R} \epsilon}$ & $\begin{array}{c}\text { ssion mode } \\
x=2\end{array}$ & $\begin{array}{c}\text { Conflict }_{x}= \\
x=3\end{array}$ & $\begin{array}{c}\beta_{1} \cdot \text { Indepe } \\
x=4\end{array}$ & $\begin{array}{c}\text { ence }+\beta_{2} . \\
x=5\end{array}$ & $\begin{array}{c}\text { Ivement }+ \\
\qquad x=6\end{array}$ & $x=7$ \\
\hline $\begin{array}{l}\beta_{0} \\
t \text {-value } \\
p\end{array}$ & $\begin{array}{l}\text { NP } \\
\text { NP } \\
\text { NP }\end{array}$ & $\begin{array}{c}-13.77^{* * *} \\
-5.36 \\
0.000\end{array}$ & $\begin{array}{l}0.07 \\
0.19 \\
0.846\end{array}$ & $\begin{array}{l}0.64^{* * *} \\
2.82 \\
0.006\end{array}$ & $\begin{array}{r}-5.76^{*} \\
-1.92 \\
0.059\end{array}$ & $\begin{array}{l}0.50 \\
0.68 \\
0.500\end{array}$ & $\begin{array}{r}-6.58^{*} \\
-1.93 \\
0.058\end{array}$ & $\begin{array}{c}-5.09^{* * *} \\
-13.73 \\
0.000\end{array}$ \\
\hline $\begin{array}{l}\beta_{1} \\
95 \% \text { conf. interval } \\
\text { t-value } \\
p \\
\text { VIF }\end{array}$ & $\begin{array}{c}\quad+ \\
\text { Overlap } \\
>2.576 \\
<0.01 \\
\text { NP }\end{array}$ & $\begin{array}{c}4.29^{* * *} \\
3.48-5.09 \\
10.68 \\
0.000 \\
1.05\end{array}$ & $\begin{array}{l}0.58^{* * *} \\
0.46-0.70 \\
9.96 \\
0.000 \\
1.05\end{array}$ & $\begin{array}{l}0.33^{* * *} \\
0.25-0.40 \\
9.13 \\
0.000 \\
1.05\end{array}$ & $\begin{array}{c}4.09^{* * *} \\
3.15-5.02 \\
8.72 \\
0.000 \\
1.05\end{array}$ & $\begin{array}{l}1.11^{* * *} \\
0.88-1.34 \\
9.64 \\
0.000 \\
1.05\end{array}$ & $\begin{array}{l}4.24^{* * *} \\
3.17-5.30 \\
7.94 \\
0.000 \\
1.05\end{array}$ & $\begin{array}{c}0.78^{* * *} \\
0.67-0.90 \\
13.60 \\
0.000 \\
1.06\end{array}$ \\
\hline $\begin{array}{l}\beta_{2} \\
95 \% \text { conf. interval } \\
\text { t-value } \\
p \\
\text { VIF }\end{array}$ & $\begin{array}{c}\quad+ \\
\text { Overlap } \\
>2.576 \\
<0.01 \\
\text { NP }\end{array}$ & $\begin{aligned} & 3.55^{* * *} \\
& 2.62-4.48 \\
& 7.65 \\
& 0.000 \\
& 1.05\end{aligned}$ & $\begin{array}{l}0.44^{* * *} \\
0.30-0.57 \\
6.47 \\
0.000 \\
1.05\end{array}$ & $\begin{array}{l}0.21^{* * *} \\
0.13-0.30 \\
9.13 \\
0.000 \\
1.05\end{array}$ & $\begin{array}{l}2.65^{* * *} \\
1.57-3.73 \\
4.88 \\
0.000 \\
1.05\end{array}$ & $\begin{array}{l}0.85^{* * *} \\
0.58-1.11 \\
6.38 \\
0.000 \\
1.05\end{array}$ & $\begin{array}{c}2.65^{* * *} \\
1.41-3.88 \\
4.29 \\
0.000 \\
1.05\end{array}$ & $\begin{array}{c}0.61^{* * * *} \\
0.47-0.74 \\
8.94 \\
0.000 \\
1.06\end{array}$ \\
\hline $\begin{array}{l}\text { Adjusted } R^{2} \\
N \\
F_{2, N-3}\end{array}$ & & $\begin{array}{l}66.45 \% \\
72 \\
71.33\end{array}$ & $\begin{array}{l}61.99 \% \\
72 \\
58.91\end{array}$ & $\begin{array}{l}56.37 \% \\
72 \\
46.87\end{array}$ & $\begin{array}{l}53.86 \% \\
72 \\
42.44\end{array}$ & $\begin{array}{l}60.64 \% \\
72 \\
55.69\end{array}$ & $\begin{array}{l}48.77 \% \\
72 \\
34.80\end{array}$ & $\begin{array}{l}76.72 \% \\
67 \\
109.67\end{array}$ \\
\hline
\end{tabular}

Table 4 presents the outcomes for estimating equation (9). We found highly significant values for the coefficients for independence and involvement ( $\beta_{1}$ and $\left.\beta_{2}\right)$ and only weakly significant results for the influence of only one control variable (companies, reflecting the number of listed companies worked for) on the constructs (negative coefficient; $0.05<p<$ 0.10). The coefficients of the other control variables are insignificant. In Table 4, we

\section{Table 4 Results estimating regression model}

PAGE $1044 \mid$ CORPORATE GOVERNANCE $\mid$ VOL. 20 NO. 62020 
reproduce the significant outcomes of testing the constructs Conflict $x, x=1, ., 6$ by estimating regression model (9) without control variables.

The outcomes in Table 4 show that all six constructs meet the requirements for measuring role conflict. The estimates of $\beta_{1}$ and $\beta_{2}$ are positive and highly significant as their $t$-values exceed 2.576 ( $p<0.01$ ). As required, their 95\% confidence intervals overlap (for most constructs, the overlapping proportions even provide support for insignificant differences between $\beta_{1}$ and $\beta_{2}$ on a 95\% confidence level). The variance inflation factor scores (VIF) indicate that the results of the regression analyses summarized in Table 4 do not suffer from multicollinearity and the (not reported) plots of the predicted values of the dependent variable vs the regression residuals do not show a heteroscedastic pattern.

We also used an alternative approach for developing the construct. We applied exploratory factor analysis (EFA) to arrive at one factor that reduces the observable variables connected to role conflict to one latent variable that is negatively associated with ScoreSpread and positively associated with ScoreLevel. Confirmatory factor analysis (CFA) was applied to test the validity of the construct. To avoid underidentification [11] we performed the CFA and the EFA using one additional observable variable besides ScoreSpread and ScoreLevel. The resulting rotated factor scores were used to measure the latent variable. The measured latent variable was compared with the constructs Conflict $t_{x}$ $x=1, ., 6$ and was used as Conflict for estimating regression model (9). The outcomes (see last column in Table 4) confirm our findings.

Consequently, we used the constructs for testing $\mathrm{H} 2$. For each construct, the average of the $(5 \times 5=) 25$ possible outcomes served as threshold for the means of the constructs based on the actual scores received from our respondents. Support for accepting $\mathrm{H} 2$ is obtained in case the means based on the 72 actual scores ( $\mu_{\text {observed }}$ ) significantly exceed the averages of the 25 possible values the construct can take ( $\mu_{\text {measure }}$ ), using the non-parametric Kruskal-Wallis test (as the samples are not normally distributed). For each of the constructs Conflict $_{x}, x=1, ., 6$, Table 5 summarizes the outcomes of applying the Kruskal-Wallis test.

The outcomes of applying the Kruskal-Wallis test are consistent with the prediction that

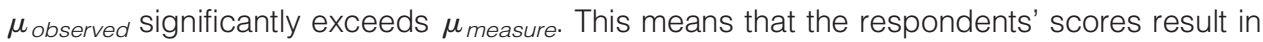
values for the composite measures that are significantly higher than the average of their 25 possible values. This result supports $H 2$.

\subsection{Robustness tests}

The aforementioned robustness tests for $\mathrm{H} 1$ and $\mathrm{H} 2$ all confirmed the outcomes. The outcomes were also confirmed by analyzing an extended data set that also comprises the responses of a comparison group of assurance partners of a big four audit firm (EY) (results not tabulated). The outcomes for the manipulation check and testing $\mathrm{H} 1$ and $\mathrm{H} 2$ conform our findings.

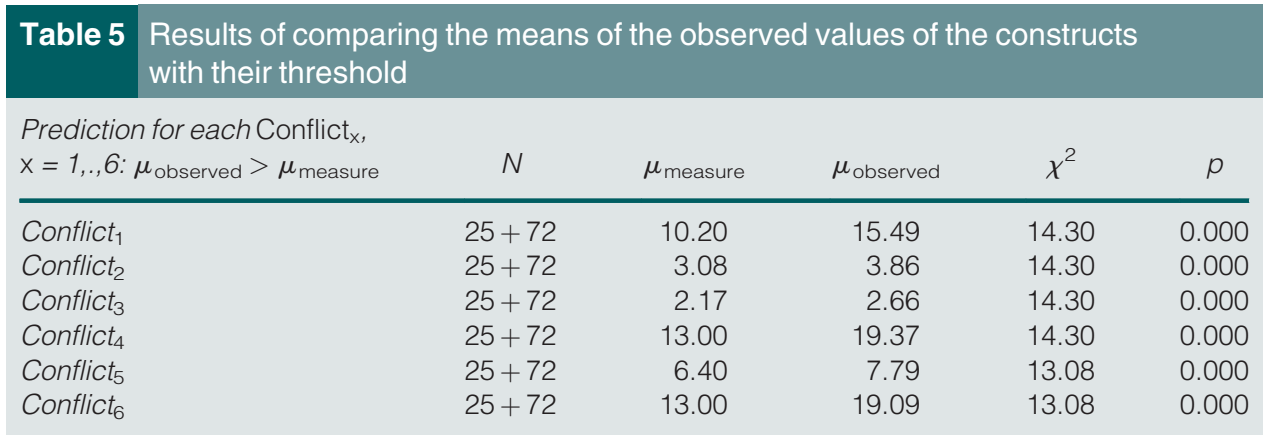




\subsection{Discussion}

Our test results indicate that the priorities attributed to controller involvement and independence under a tight regime are similar to those for the loose regime. This is also consistent with other findings of our study. First, the preference for a hierarchical reporting line to the $\mathrm{BU}$ manager (reporting line model 1) when an independent role is preferred is substantial and approximately equally strong as the preference for a hierarchical reporting line to the corporate controller/CFO (model 2) which intrinsically enhances controller independence. Second, the significant association of preferred controller involvement and the preference for a hierarchical reporting line to the BU manager (reporting line model 1) means that respondents noticed the differences between the models and differentiated their preferences.

The idea of prioritizing independence as a result of tightening corporate governance rules and regulations [as expressed by a/o Byrne (2009) and Indjejikian and Matějka (2009)] is echoed by the observed scores on the continuum between involvement and independence. These scores point to a preference for independence, which is more significant for the tight case than for the loose case, but were contradicted by the preferred levels of independence and involvement. An explanation could be that, irrespective of the governance regime, the supervisory board members see the relevance of both roles and feel the need to balance them and manage the potential role conflict, which is in accordance with the insights gained from the work of Sathe (1982), Maas and Matějka (2009), Chang et al. (2014) and Merchant and Van der Stede (2017).

Also from an agency theoretical perspective, the results of our study have some noteworthy implications. First, our results suggest that supervisory board members require management to establish the conditions that enable and incentivize the $\mathrm{BU}$ controller (the agent) to deliver on the expectations of the BU manager and the CFO (the two principals), who arguably balance the importance of the involved decisionmaking role and the independent fiduciary role differently. Second, the outcomes of our study suggest that supervisory board members seem to accept role conflict as a consequence of maintaining a balanced fulfillment of both controller roles when the pressure to emphasize one (e.g. the dependent role) increases (e.g. because of a tight governance regime).

Finally, our study underscores the relevance of balancing independence and involvement and handling role conflict. Arguably, this takes "strong controllers" who possess the ability to remain actively involved in business decision-making processes while retaining a sense of objectivity and independence in dealing with management (Sathe, 1982). Organizations can support strong controllers by creating a culture that encourages high degrees of both independence and involvement and providing conditions to deal with role conflict.

\section{Conclusions and limitations}

\subsection{Conclusions}

$\mathrm{BU}$ controllers balance two major roles: the independent role necessary for producing reliable financial reporting and ensuring effective internal control; and the involved role for supporting management decision-making. Using data from a survey-based experiment with supervisory board members, we test whether the tightness of the governance regime positively affects the preferred level of $\mathrm{BU}$ controller independence and negatively affects the preferred level of $\mathrm{BU}$ controller involvement. We find that while the supervisory board members have recognized and understood the difference in tightness, they advocate substantial levels of $\mathrm{BU}$ controller independence and involvement, which are not affected by the tightness of the governance regimes. We find evidence for the preference to balance these roles and the recognition that this could induce role conflict. Our findings could mean 
that the sample group of supervisory board members prefers BU controllers who demonstrate involved and independent behavior in a tight and a loose governance regime, and can deal with role conflict.

Taken together, our study suggests that irrespective of the tightness of the governance regime, supervisory board members recommend BU controllers to remain independent from and involved with their management. The increased focus on corporate governance guidelines and regulations and their potential impact on the control function make the controller's independence important. At the same time, controllers are more involved in the decision-making processes of the BU management than ever before, feeding the preference for an involved controller. These two parallel developments could explain why we find that the governance regime fails to explain the preferred role of the $\mathrm{BU}$ controller. Our findings could be indicative for the preference for an "all-round" controller who balances the two main roles and deals with role conflict in both settings.

\subsection{Limitations}

These conclusions are subject to limitations. First, the two case descriptions used to distinguish between a tight and a loose governance regime were tested only once before, in a pilot experiment, and not in prior research. We developed the case descriptions based on a theoretical framework consisting of the main variables in the research. Respondents may have had a different interpretation of the organization in their case owing to their background and experience. We limited this potential effect by randomly distributing the two types of case descriptions among the respondents.

Second, we created an experimental setting in the case descriptions, which, in comparison with a real-life setting, could harm the generalizability of the results. This is a common limitation of experiments. We mitigated this risk by creating realistic organization descriptions. Moreover, the experiment was not fully controlled in a laboratory setting; rather, the case descriptions and the questionnaire were sent to the sample. That said, we do not expect that this has distorted the responses. It seems very unlikely that respondents would have interacted about the study and that these interactions were on such detailed level that they led respondents to come up with mutually agreed-on responses.

Third, we did not have direct observations of perceptions regarding controller role conflict but constructed and tested measures that exhibit features that are typical for role conflict. Although these measures are likely to deviate from direct observations, they mirror properties of role conflict and avoid additional questions and related risks of misinterpretation.

Fourth, the statistical evidence for our hypothesis regarding the influence of the governance regime on the preferred controller role is limited. It supports the conclusion that the (confirmative) null-hypothesis could not be rejected. Additional analyses provided some evidence in favor of the hypothesis.

Despite these limitations, we believe our study contributes to understanding views of supervisory board members on the roles relevant for $\mathrm{BU}$ controllers and the extent to which governance regime tightness influences the relevance of the roles and the conflict between the roles. This topic, in combination with the experimental research method, has received little attention in prior research.

\section{Notes}

1. The relevance of the framework of Sathe $(1982,1983)$ has also been evidenced by Zoni and Merchant (2007) (who build on Sathe's framework and found that controller involvement is positively associated with performance) and by Ten Rouwelaar et al. (2008) [who build on Zoni and 
Merchant (2007) and examine both organizational and personal characteristics of BU controllers and their impact on the degree of BU controller involvement in decision-making].

2. During interviews with supervisory board members, we learned that despite of their indirect relationship with $\mathrm{BU}$ controllers, they have clearly articulated opinions on how BU controllers should act within organizations, and related aspects including reporting lines and the balance of independence and involvement.

3. Here we use the terminology of Indjejikian and Matějka (2009, p. 1061).

4. We follow the typical role descriptions that can be found in corporate governance codes, such as the ones that are enacted in the USA, Germany, UK and The Netherlands. See the Sarbanes-Oxley Act of 2002 (Pub.L. 107-204, 116 Stat. 745, enacted July 30, 2002), Higgs (2003), Cromme (2005) and Corporate Governance Code Monitoring Committee (2012).

5. Byrne (2009, p. 57) speaks of MAs and argues that "the control function is an integral component of the roles of MAs." In line with Merchant and Van der Stede (2017), we will refer to the controller as the person in organizations that plays a "key role in line management and in the design and operation of a management control system."

6. www.financialexecutives.org

7. An example of a rule-based governance mechanism is the Anglo-Saxon governance regime, while the Rhineland governance regime is an example of the principle-based governance mechanism. This distinction is similar to the distinction between the "Anglo-American system" and the "Continental European/Japanese system" made by Merchant and Van der Stede (2017), but avoids a position on geographies outside the scope of our study (e.g. France, which is a Continental European but not a Rhineland country, and Japan).

8. Royall (1997) argues that power-to-alpha likelihood ratios below 8 point to weak evidence, whereas values exceeding 8 (32) correspond with moderate (strong) evidence.

9. The (not tabulated) results of an ANOVA test confirm the strong relation between a high (low) preference for controller involvement and a preference for a hierarchical (functional or hierarchical) line to the BU manager and a functional (hierarchical) line to the corporate controller (F-value: 3.98; p-value: 0.023).

10. This model was tested using ordinary least squares and the standard robustness tests (heteroscedasticity, normality, multicollinearity and linearity).

11. Hair et al. (2006, p. 784) and Raubenheimer (2004, p. 60).

\section{References}

Aguilera, R.V. and Cuervo-Cazurra, A. (2009), "Codes of good governance", Corporate Governance: An International Review, Vol. 17 No. 3, pp. 376-387.

Albers, C.A. and Kratochwill, T.R. (2010), "Design of experiments", in Perterson, P., Baker, E. and McGraw, B. (Ed.), International Encyclopedia of Education, (Third Edition), Elsevier, Oxford, pp. 125-131.

Anthony, R.N. and Govindarajan, V. (2007), Management Control Systems, McGraw-Hill, Boston.

Brent, J.C. (1999), "An agent and two principals - U.S. Court of appeals responses to employment division, department of human resources v. Smith and the religious freedom restoration act", American Politics Quarterly, Vol. 27 No. 2, pp. 236-266.

Burns, J. and Scapens, R.W. (2000), "Conceptualizing management accounting change: an institutional framework", Management Accounting Research, Vol. 11 No. 1, pp. 3-25.

Burns, J., Scapens, R. and Turley, S. (1996), "Some further thoughts on the changing practice of management accounting", Management Accounting, Vol. 74 No. 9, pp. 58-60.

Busco, C., Giovannoni, E., Riccaboni, A., Franceschi, D. and Frigo, M.L. (2007), "Linking governance to strategy: the role of the finance organization", Strategic Finance, Vol. 89 No. 3, pp. 23-28.

Byrne, S. (2009), "Antecedents, characteristics, and consequences associated with the roles of management accountants, and assisting managers in their roles", Dissertation, Dublin City University Business School, Dublin.

Byrne, S. and Pierce, B. (2007), "Towards a more comprehensive understanding of the roles of management accountants", European Accounting Review, Vol. 16 No. 3, pp. 469-498. 
Calder, A. (2008), Corporate Governance: A Practical Guide to the Legal Frameworks and International Codes of Practice, Kogan Page Publishers, London.

Chang, H., Ittner, C. and Paz, M.T. (2014), "The multiple roles of the finance organization: determinants, effectiveness, and the moderating influence of information system integration", Journal of Management Accounting Research, Vol. 26 No. 2, pp. 1-32.

Colton, S.D. (2001), "The changing role of the controller", Journal of Cost Management, Vol. 15 No. 6 , pp. 5-10.

Corporate Governance Code Monitoring Committee (2012), Dutch Corporate Governance code Principles of Good Corporate Governance and Best Practice Provisions, Ministry of Finance and Ministry of Economic Affairs, The Hague.

Cromme, G. (2005), "Corporate governance in Germany and the German corporate governance code", Corporate Governance: An International Review, Vol. 13 No. 3, pp. 362-367.

Cumming, G. and Fidler, F. (2005), "Interval estimates for statistical communication: problems and possible solutions", IASE/ISI Satellite Conference Proceeding, pp. 1-7.

De Loo, I., Nederlof, P. and Verstegen, B. (2006), "Detecting behavioural patterns of Dutch controller graduates through interpretive interactionism principle", Qualitative Research in Accounting \& Management, Vol. 3 No. 1, pp. 46-66.

De Loo, I., Verstegen, B. and Swagerman, D. (2011), "Understanding the roles of management accountants", European Business Review, Vol. 23 No. 3, pp. 287-313.

Eisenhardt, K.M. (1989), "Agency theory: an assessment and review", Academy of Management Review, Vol. 14 No. 1, pp. 57-74.

Fan, X. (2001), "Statistical significance and effect size in education research: two sides of a coin", The Journal of Educational Research, Vol. 94 No. 5, pp. 275-282.

Feeney, O. and Pierce, B. (2007), "Today's management accountant: honest bean counter and savvy business advisor?”, Management Accounting, Vol. 39 No. 5, pp. 16-21.

Friedman, H. (2012), "The role and responsibilities of the CFO: implications for reporting quality, firm value, and incentive compensation", Working paper, University of California, Los Angeles.

Friedman, H.L. (2014), "The strategic CFO? Implications of the CFO's role and responsibilities", Working paper, available at SSRN: https://ssrn.com/abstract=2160046 or http://dx.doi.org/10.2139/ ssrn.2160046

Gailmard, S. (2009), "Multiple principals and oversight of bureaucratic policy-making", Journal of Theoretical Politics, Vol. 21 No. 2, pp. 161-186

Ge, W., Matsumoto, D. and Zhang, J.L. (2011), "Do CFOs have style? An empirical investigation of the effect of individual CFOs on accounting practices", Contemporary Accounting Research, Vol. 28 No. 4, pp. 1141-1179.

Graham, A., Davey-Evans, S. and Toon, I. (2012), "The developing role of the financial controller: evidence from the UK", Journal of Applied Accounting Research, Vol. 13 No. 1, pp. 71-88.

Granlund, M. and Lukka, K. (1998), "Towards increasing business orientation: Finnish management accountants in a changing cultural context", Management Accounting Research, Vol. 9 No. 2, pp. 185-211.

Hahn, D. (1982), "The control function in major German companies", Long Range Planning, Vol. 15 No. 3, pp. 21-50.

Hair, J.F., Black, W.C., Babin, B.J., Anderson, R.E. and Tatham, R.L. (2006), Multivariate Data Analysis, Sixth Edition, Pearson Prentice Hall, Upper Saddle River.

Ham, C., Lang, M., Seybert, N. and Wang, S. (2017), "CFO narcissism and financial reporting quality", Journal of Accounting Research, Vol. 55 No. 5, pp. 1089-1135.

Higgs, D. (2003), Review of the Role and Effectiveness of Non-Executive Directors, Department of Trade and Industry, London.

Horngren, C.T., Datar, S.M. and Rajan, M.V. (2015), Cost Accounting - a Managerial Emphasis, Pearson Global Edition, Harlow, England. 
Howell, R.A. (2006), "The CFO: from controller to global strategic partner", Financial Executive, Vol. 22 No. 3, pp. 20-25.

IFAC (International Federation of Accountants) (2002), The Role of the Chief Financial Officer in 2010, IFAC, New York, NY.

Indjejikian, R. and Matějka, M. (2009), "CFO fiduciary responsibilities and annual bonus incentives", Journal of Accounting Research, Vol. 47 No. 4, pp. 1061-1093.

Järvenpää, M. (2007), "Making business partners: a case study on how management accounting culture was changed", European Accounting Review, Vol. 16 No. 1, pp. 99-142.

Jensen, M.C. and Meckling, W.H. (1976), "Theory of the firm: managerial behavior, agency costs and ownership structure", Journal of Financial Economics, Vol. 3 No. 4, pp. 305-360.

Joseph, G. (2006), "Understanding developments in the management information value chain from a structuration theory framework", International Journal of Accounting Information Systems, Vol. 7 No. 4, pp. 319-341.

Kerlinger, F.N. (1986), Foundations of Behavioral Research, third edition, Holt, Rinehart and Winston, New York, NY.

Lambert, C. and Sponem, S. (2005), "Corporate governance and profit manipulation: a French field study", Critical Perspectives on Accounting, Vol. 16 No. 6, pp. 717-748.

Larsén, M.F. (2007), "Principal-agent analysis with one agent and two principals: European union trade negotiations with South Africa", Politics \& Policy, Vol. 35 No. 3, pp. 440-463.

Maas, V.S. and Matějka, M. (2009), "Balancing the dual responsibilities of business unit controllers: field and survey evidence", The Accounting Review, Vol. 84 No. 4, pp. 1233-1253.

Merchant, K.A. (1985), Control in Business Organizations, Ballinger Publishing, Cambridge, MA.

Merchant, K.A. and Van der Stede, W.A. (2017), Management Control Systems, Fourth Edition, Pearson, Harlow, England.

O'Shea, N. (2005), "Governance: How we've got where we are and what's next", Accountancy Ireland, Vol. 37 No. 6, pp. 33-37.

Raubenheimer, J. (2004), "An item selection procedure to maximise scale reliability and validity", SA Journal of Industrial Psychology, Vol. 30 No. 4, pp. 59-64.

Reiser, B. and Faraggi, D. (1999), "Confidence intervals for the overlapping coefficient: the normal equal variance case", Journal of the Royal Statistical Society: Series D (the Statistician)), Vol. 48 No. 3, pp. 413-418.

Roozen, F. and Steens, B. (2006), "Environmental influence on the role and requirements of finance professionals: evidence from corporates in The Netherlands", Reflections on the Future of Finance and Control: Creating a Knowledge Management Environment Supporting Continuous Learning, Kluwer, Deventer, The Netherlands, pp. 23-46.

Royall, R. (1997), Statistical Evidence: A Likelihood Paradigm, Chapman \& Hall, London; New York, NY.

Russel, K.A., Siegel, G.H. and Kulesza, C.S. (1999), "Counting more, counting less", Strategic Finance, Vol. 81 No. 3, pp. 38-44.

Sathe, V. (1982), Controller Involvement in Management, Prentice Hall, Englewood Cliffs.

Sathe, V. (1983), "The controller's role in management", Organizational Dynamics, Vol. 11 No. 3 , pp. 31-48.

Scapens, R.W. (2006), "Understanding management accounting practices: a personal journey", The British Accounting Review, Vol. 38 No. 1, pp. 1-30.

Smith, G.D. and Morris, P.E. (2015), "Building confidence in confidence intervals", The Psychologist, Vol. 28 No. 6, pp. 476-479.

Ten Rouwelaar, J.A., Bots, J. and Vanamelsfort, M. (2008), "Business unit controller involvement in management - an empirical study in The Netherlands", working paper available at SSRN: https://ssrn. com/abstract=1277863 or http://dx.doi.org/10.2139/ssrn.1277863, pp. 1-39.

Trotman, K.T., Tan, H.C. and Ang, N. (2011), "Fifty-year overview of judgment and decision-making research in accounting", Accounting \& Finance, Vol. 51 No. 1, pp. 278-360. 
Van der Stede, W., (2010), and Malone, R. Accounting Trends in a Borderless World, Chartered Institute of Management Accountants, London.

Weber, J. (2011), "The development of controller tasks: explaining the nature of controllership and its changes", Journal of Management Control, Vol. 22 No. 1, pp. 25-46.

Wieland, J. (2005), "Corporate governance, values management, and standards: a European perspective", Business \& Society, Vol. 44 No. 1, pp. 74-93.

Windeck, D., Weber, J. and Strauss, E. (2015), "Enrolling managers to accept the business partner: the role of boundary objects", Journal of Management \& Governance, Vol. 19 No. 3, pp. 617-653.

Zoni, L. and Merchant, K.A. (2007), "Controller involvement in management: an empirical study in large Italian corporations”, Journal of Accounting \& Organizational Change, Vol. 3 No. 1, pp. 29-43.

\section{Corresponding author}

Bert Steens can be contacted at: h.b.a.steens@vu.nl

For instructions on how to order reprints of this article, please visit our website: www.emeraldgrouppublishing.com/licensing/reprints.htm

Or contact us for further details: permissions@emeraldinsight.com 